\title{
Comunicação e saúde: interfaces e desafios
}

Communication and health: interfaces and challenges

Comunicación y salud: interfaces y desafíos

\section{Maria Rosana Ferrari Nassar}

- Doutora e mestre e em Ciências da Comunicação pela Escola de Comunicações e Artes da Universidade de São Paulo (ECA-USP)

- Professora da Faculdade de Relações Públicas da Pontifícia Universidade Católica de Campinas (Puccamp) desde 1985

- Assessora de comunicação e marketing para organizações de saúde e palestrante em eventos da área de saúde.

- Membro do Conselho Regional dos Profissionais de Relações Públicas da $2^{\mathrm{a}}$ Região - Conrerp SP/PR

- Publicou artigos em revistas científicas e anais de eventos da área de comunicação e saúde no Brasil e no exterior

- E-mail: mktsaude@yahoo.com.br 


\section{Resumo}

Este artigo apresenta uma reflexão crítica sobre comunicação e saúde em uma sociedade na qual informação e conhecimento representam categorias amplamente valorizadas. Focalizando a formação médica, propõe a inserção da comunicação nos currículos de graduação e pós-graduação como modo de desenvolver competências para o exercício profissional humanizado, especificamente no que diz respeito ao relacionamento com o paciente.

PALAVRAS-CHAVE: COMUNICAÇÃO • SAÚDE • CURRÍCULO • PRÁTICA MÉDICA

\section{Abstract}

This article presents a critical reflection on communication and health in a society where information and knowledge represent categories that are widely valued. Focusing on medical education it proposes the inclusion of communication in undergraduate curricula and graduate programs as a way to develop skills for humanized professional performance, specifically concerning the relationship with the patient.

KEYWORDS: COMMUNICATION • HEALTH • CURRICULUM • MEDICAL PRACTICE

\section{Resumen}

Este artículo presenta una reflexión crítica sobre la comunicación y la salud en una sociedad donde la información y el conocimiento representan categorías ampliamente valoradas. Centralizándose en la educación médica, propone la inclusión de la comunicación en los programas de pregrado y posgrado como una forma de desarrollar habilidades para el ejercicio profesional humanizado, específicamente en lo que respecta al relacionamiento con el paciente.

PALABRAS CLAVE: COMUNICACIÓN • SALUD • CURRÍCULO • PRÁCTICA MÉDICA 
O paradigma científico moderno propiciou uma nova visão do mundo e da vida baseada na oposição a toda forma de dogmatismo e de autoridade. A ciência moderna se opôs ao conhecimento do senso comum: o único conhecimento válido é o conhecimento científico, obtido pela observação sistemática e com o maior rigor possível dos fenômenos naturais. Na perspectiva da modernidade, a ideia de mundo assemelha-se a uma máquina, operada segundo as leis da física e da matemática e por isso dotado de previsibilidade. Esse modelo de racionalidade técnica e mecanicista tem sido hegemônico desde a revolução científica do século XVI e em grande parte foi responsável pela crença no progresso incessante, no planejamento racional, na capacidade da ciência e da razão, bem como na conquista da igualdade social como um destino natural.

Como cidadãos contemporâneos, conhecemos bem os limites desse modelo e a crise vivenciada pela ciência. Para Boaventura de Sousa Santos (1995, p. 6), o campo científico vive "um tempo de transição, síncrono com muita coisa que está além ou aquém dele, mas descompassado em relação a tudo que o habita". É um tempo complexo em que impera a ambiguidade e a contradição: de um lado, todo potencial da revolução tecnológica leva-nos a crer em uma sociedade de comunicação e interatividade; de outro, uma profunda reflexão sobre os limites da ciência combinado com as ameaças ao meio ambiente, da violência em geral e da violência das guerras.

Esse tempo de transição, identificado como momento de crise do paradigma moderno, repercute no campo científico. A área da saúde, assim como qualquer outra área do conhecimento, constituiu-se sob a égide desse paradigma científico, caracterizado pela racionalidade técnica e total separação entre natureza e ser humano, seguindo a lógica do conhecer para controlar/dominar (Santos, 1995, p. 10). Mas, diante de seus limites em responder aos problemas sociais e do próprio processo saúde-doença, as ciências da saúde vivenciam também uma crise: o atual contexto socioeconômico, político e tecnológico tem demandado um novo conceito de saúde, capaz de responder aos desafios contemporâneos.

Há alguns anos a ideia de saúde passou da mera ausência da doença para a noção de bem-estar físico e mental. E mais recentemente adotou-se um conceito mais amplo, que compreende a saúde como produção social, ou seja, pelo qual a saúde-doença é compreendida como um processo complexo. Essa transição teórica perpassa as práticas, as políticas de saúde pública e necessariamente a formação dos profissionais. É, pois, com base em nova perspectiva epistemológica que este artigo apresenta uma discussão sobre a relevância das competências comunicativas na formação do médico, a educação como forma de responder ao novo contexto social, político e tecnológico e as próprias mudanças teóricas nas ciências da saúde.

A ciência e o desenvolvimento tecnológico são marcas da sociedade contemporânea. Conhecimento e informação são elementos que se juntaram ao capital como sinônimo de poder, ainda que continuem sendo distribuídos de forma desigual. Capital e conhecimento constituem-se em elementos estratégicos da nova era, marcada pela crescente inovação tecnológica. No que diz 
respeito aos serviços de saúde, a avalanche tecnológica potencializou o caráter excludente do conhecimento científico e da tecnologia que ele produz, visto que significativa parcela da população não tem acesso aos cuidados básicos com a saúde.

É nesse cenário que o presente texto objetiva abordar a relação entre comunicação e saúde. Pretende-se provocar uma reflexão, particularmente, sobre a importância da comunicação na construção da prática médica humanizada, por meio da análise crítica sobre a formação do médico, sem a intenção de esgotar o assunto, pois o que aqui se propõe constitui um dos muitos enfoques pelos quais a interação entre comunicação e saúde pode ser estudada. Para dar conta desse objetivo, o artigo está organizado em três tópicos, além desta introdução e das considerações finais. O primeiro tópico, "Cenários da saúde e da formação do médico no Brasil", apresenta sinteticamente um panorama da saúde e do ensino médico no país. O segundo, "Modelos de formação médica e características dos perfis profissionais: da ênfase na doença à enfase na promoção da saúde", apresenta o embate epistemológico entre duas concepções de saúde e as repercussões desses modelos na formação dos médicos. Finalmente, o terceiro tópico, "A importância da comunicação na formação do médico", apresenta a proposta de inserção de disciplina de comunicação nos currículos, como forma de preparar competências para a prática médica humanizada.

\section{CENÁRIO DA SAÚDE E DA FORMAÇÃO DO MÉDICO NO BRASIL}

A Constituição Federal de 1988 instituiu o Sistema Único de Saúde (SUS), orientado pelos princípios da democratização do acesso, da distribuição equitativa de recursos e da justiça social. Ela vê a saúde como um direito social, resultante de condições de vida e trabalho, "garantida mediante políticas sociais e econômicas, que visem à redução do risco de doença e outros agravos e ao acesso universal e igualitário às ações e serviços para sua promoção, proteção e recuperação" (Brasil, 2003). Essa definição reflete uma abordagem da saúde como produção social, consoante o paradigma da integralidade, segundo o qual ser saudável significa a possibilidade de produzir a própria saúde, mediante os cuidados tradicionais, mas também por ações políticas que visem à redução das desigualdades, ao acesso à educação, à participação social na gestão de recursos públicos etc. É evidente, pois, a relação entre saúde e cidadania. Não por acaso, a saúde passa a integrar a categoria dos direitos sociais do cidadão, associada a outros como direito à moradia digna, à alimentação, ao trabalho e à renda, ao lazer, ao meio ambiente preservado, dentre outros. Tal reconhecimento no âmbito jurídico tem demandado ações no sentido de tornar esses direitos efetivos, o que significa, por exemplo, ações educativas no sentido de preparar profissionais para atender as necessidades sociais em saúde.

No campo educacional, por sua vez, as mudanças também têm sido significativas, ao menos em termos quantitativos. Como resultado da política expansionista iniciada na década de 1990, o país forma atualmente aproximadamente 16 mil médicos por ano, oriundos de 185 escolas. Em 2011 
foram disponibilizadas 16,8 mil vagas, segundo dados do Conselho Federal de Medicina e do Conselho Regional de Medicina de São Paulo. Em outubro de 2011, o CFM contabilizava 371.788 médicos em atividade no Brasil. De 1970 a 2011 registrou-se um aumento de 530\% nesse número, enquanto a população brasileira cresceu 104\% (Cardoso, 2011, p. 15).

Entre 188 países, o Brasil, fica atrás apenas da China, dos Estados Unidos, da Índia e da Rússia em números absolutos desses profissionais. Proporcionalmente, registra-se uma razão de 1,95 médicos por mil habitantes, embora distribuídos de modo desigual, em razão das disparidades regionais, do mercado de trabalho, da concentração de renda e das especialidades médicas (Escolas Médicas do Brasil, 2012). Em outras palavras, os médicos, assim como outros profissionais da saúde, tendem a permanecer em estados e regiões mais desenvolvidos: no Sudeste, o índice é de 2,6 médicos por mil habitantes; e no Norte, é de 0,8. Somente no estado de São Paulo existem 33 escolas médicas (Cardoso, 2011).

Do total de cursos existentes em 2012, 39\% (73) são oferecidos por instituições públicas e 61\% (115), por instituições de ensino privadas. Como resultado do processo de expansão do ensino superior iniciado na década de 1990, ampliou-se consideravelmente o número de escolas médicas no Brasil, sobretudo aquelas mantidas pela iniciativa privada: de 2000 a 2011, 77 escolas médicas foram criadas, em sua maioria particulares (Instituto Salus, 2012). A proliferação indiscriminada de cursos e a ampliação de vagas em cursos já existentes têm sido objeto de contestação de entidades médicas, em razão da queda na qualidade da formação acadêmica e do aviltamento da remuneração profissional.

No que diz respeito ao mercado de trabalho, conforme assinala Mário Scheffer $(2011$, p. 11-12), "a prática médica tem migrado do exercício liberal - o médico trabalhava onde queria, com os horários que escolhia e a remuneração que determinava - para uma prática no seio de organismos públicos e privados". O autor complementa:

A expansão do Sistema Único de Saúde (SUS) e a ampliação do segmento regulamentado de planos e seguros de saúde privados intensificaram mecanismos de intervenção do Estado e do mercado sobre a profissão médica.

Diante da organização fragmentada do sistema de saúde brasileiro, a profissão assumiu determinados perfis. Hoje, a maioria dos médicos tem vínculos públicos e privados, cumprem carga horária de trabalho excessiva e acumulam vários empregos. A jornada de trabalho dos médicos é, em média, superior a 50 horas semanais e quase um terço dos profissionais trabalha mais de 60 horas por semana. Os médicos atuam em média em três diferentes postos de trabalho, sendo que mais de $30 \%$ acumulam quatro ou mais locais de trabalho, dividindo a atuação em consultório, com recebimento por produção, com a atuação geralmente assalariada em serviços públicos e privados. 
Apesar do avanço jurídico-formal, o setor público, de modo geral, não se mostra atrativo para os profissionais de saúde, particularmente para os médicos. E os principais entraves parecem ser a forma de financiamento do SUS, a ausência de carreiras médicas, a baixa remuneração e as precárias condições de trabalho. De qualquer forma, apesar de a profissão ainda despertar o interesse de muitos e de ocupar lugar de destaque quando se consideram indicadores de empregabilidade, observa-se um cenário de precarização do trabalho médico, particularmente no setor público. Isto porque, "além da distribuição injusta de médicos, não são poucas as desigualdades geradas por uma estrutura de financiamento e de oferta de serviços que privilegia o privado no sistema de saúde brasileiro" (CFM/Cremesp, 2011, p. 52).

Por outro lado, pode-se considerar que a institucionalização do SUS expôs algumas deficiências do sistema educacional brasileiro, notamente no que diz respeito à formação de profissionais de saúde para atender às novas exigências sociais. Na formação do médico passou-se a questionar a sua qualificação para fazer frente às necessidades básicas da sociedade quanto à atenção integral à saúde. Independentemente do setor de atuação, público ou privado, considerando a perspectiva da mudança de paradigma a que já nos referimos anteriormente, as escolas médicas têm o desafio e o compromisso social de transformar o ensino médico, oferecendo à sociedade médicos mais competentes, humanos e éticos:

O processo de produção de médicos não é um processo isolado, relaciona-se intimamente à estrutura econômica, determina, como acontece com todos os demais componentes da sociedade, a importância, o lugar e a forma da medicina na estrutura social (Almeida, 1999, p. 124).

Não se pode perder de vista que a formação médica reflete a crise geral e reproduz as deficiências e injustiças do sistema político e econômico e o modo de organização dos sistemas de saúde. De tal sorte que, em relação ao ensino médico, se pode afirmar que "falha [ou tem falhado] no seu objetivo primordial de promover a formação clínica e humana do médico" (Galizzi Filho, 2002, p. 111).

Para além dos problemas estruturais do sistema de saúde, não podemos ignorar que, conforme assinala Jadete Lampert (2002, p. 2), apesar do significativo número de profissionais formados e imediatamente autorizados a exercer a medicina,

a realidade mostra que há escassez de médicos para atender as NBS [necessidades básicas de saúde] e que a população, de uma forma geral, não está atendida ou está insatisfeita com o atendimento recebido em saúde.

A autora ainda destaca o alto custo social da formação de médicos quando se leva em conta a longa duração do curso de medicina (seis anos). Isto nos leva a considerar, então, os problemas estruturais de um outro sistema nacional, o educacional. 
O ensino superior brasileiro tem passado por algumas mudanças desde a década de 1990 . Sob a perspectiva da modernização (formar profissionais com as competências exigidas pelo novo mercado de trabalho) e da ampliação do acesso, o país viveu um surto expansionista inédito. Surgiram inúmeras instituições de ensino superior, principalmente no setor privado. Ampliou-se significativamente a oferta de vagas em cursos de graduação. $\mathrm{Na}$ área da saúde, particularmente para os cursos de medicina, essa expansão tem merecido críticas, sob o argumento de tem contribuído para a precarização da profissão e também para queda na qualidade dos serviços médicos. A lógica é simples: médicos formados em instituições fracas e mal estruturadas não terão as competências técnicas mínimas. Além da expansão desmedida, há que se considerar outro problema, este de natureza epistemológica, pedagógica e prática. Melhor dizendo: o ensino médico vive o desafio de se reinventar quanto à perspectiva epistemológica, o que implica diretamente o modo de formação: que tipo de médico se pretender formar? Para exercer qual medicina?

\section{MODELOS DE FORMAÇÃO MÉDICA E CARACTERÍSTICAS DOS PERFIS PROFISSIONAIS: DA ÊNFASE NA DOENÇA À ENFASE NA PROMOÇÃO DA SAÚDE}

Lampert (2002, p. 8) afirma com bastante propriedade que "a maneira como se organiza e se pensa a formação produz um resultado diferenciado das práticas sociais". Considerando a perspectiva proposta pela autora, podemos identificar dois modelos básicos de formação de médicos. O primeiro, ainda hegemônico no Brasil, é baseado ou influenciado "pelos estudos de Flexner, divulgados no relatório de mesmo nome e conhecido como paradigma flexneriano", caracterizando-se pela fragmentação do conhecimento em especialidades, na organização das escolas em departamentos e de disciplinas isoladas com pouca ou nenhuma interação (Lampert, 2002, p. 33-34).

Em decorrência, chega-se ao ponto em que as escolas médicas se encontram oferecendo um curso de graduação em Medicina altamente questionado na sua terminalidade, quanto à sua capacidade de formar o profissional para o mercado de trabalho, e apresentando dificuldade de mostrar unidade na composição do que preconizam (Lampert, 2002, p. 34).

Em consequência desse modelo, a medicina é ensinada de forma "essencialmente individualista, biologicista, hospitalocêntrica e com ênfase nas especializações" (Lampert, 2002, p. 34). Esse modelo começou a ser questionado a partir da década de 1960, principalmente em razão de ter contribuido para o distanciamento da "abordagem da saúde do ser humano como um todo, inteiro e único no seu contexto". Desse movimento nasceram ideias como a medicina preventiva e a promoção da saúde como qualidade de vida, conforme assinala Lampert (2002, p. 8 e 35):

Isso se fez com a identificação dos determinantes da saúde situados no biológico e além dele, no estilo de vida do indivíduo e no meio ambiente em que se insere, os quais são elementos 
fundamentais para compor uma existência saudável. No Brasil, o modelo da medicina preventiva e da promoção da saúde teve na VIII Conferência Nacional da Saúde (1986) e no movimento da Reforma Sanitária seus dois marcos históricos fundamentais. Sua construção influiu, decisivamente, na formulação das políticas constitucionais do setor da saúde, o que pode ser constatado no título VIII (Da ordem social), capítulo II (Da seguridade social), em que está escrito que "saude é direito de todos e dever do Estado" (art. 196 da Constituição Brasileira de 1988) (Lampert, 2002, p. 34).

Esse novo modelo, denominado paradigma da integralidade em razão de perspectiva holística do ser humano, contrapondo-se ao paradigma flexneriano, pressupõe a formação do médico capaz de almalgamar o saber técnico e o saber social. Para tanto, a formação precisaria focalizar o processo saúde-doença a partir das "dimensões sociais, econômicas e culturais da vida da população", afirma Lampert (2002, p. 36 ) que complementa:

O paradigma da integralidade induziria à construção de um novo modelo pedagógico, visando ao equilíbrio entre excelência técnica e relevância social. Esse princípio operativo a nortear o movimento de mudança, por sua vez, deveria estar sustentado na integração curricular, em modelos pedagógicos mais interativos, na adoção de metodologias de ensino-aprendizagem centradas no aluno como sujeito da aprendizagem e no professor como facilitador do processo de construção de conhecimento (Feuerwerker; Sena, 1999). As interações suporiam relações de parceria entre as universidades, os serviços e grupos comunitários.

Essa concepção tem como fundamento a visão integral de homem como fim de todo conhecimento e de todas as estruturas e organizações sociais criadas. Daí a origem do conceito de humanização da medicina, que compreende, portanto, um amplo espectro, abrangendo os modelos de gestão, a formação integral de médicos e outros profissionais da área da saúde; a assistência multidisciplinar; a promoção da saúde; a prevenção; a educação; a garantida do acesso às tecnologias e aos procedimentos modernos; o respeito aos direitos do paciente e sua autonomia.

\section{A IMPORTÂNCIA DA COMUNICAÇÃO NA FORMAÇÃO DO MÉDICO}

As Diretrizes Curriculares Nacionais, fixadas em 2002 pelo Conselho Nacional de Educação/CES (Parecer CNE/CES 104/2002), para o curso de graduação em medicina são evidências concretas da transição de modelos de formação, ao pretender garantir flexibilidade, diversidade e qualidade da formação, preconizando a articulação com as diretrizes do SUS. Essas diretrizes orientam a construção de currículos baseados em valores como qualidade, eficiência e resolutividade para capacitar profissionais com autonomia e discernimento, competentes para assegurar a integrali- 
dade da atenção, a qualidade e a humanização do atendimento prestado aos indivíduos, às suas famílias e às comunidades. Estabelece, entre as competências gerais a serem desenvolvidas, a comunicação e reforça que os currículos devem contemplar as ciências humanas e sociais, referindo-se especificamente a conteúdos que envolvam a comunicação'.

Refletem, portanto, a necessidade de conceber currículos capazes de acolher novas abordagens e perspectivas destinadas à formação generalista, humanista, crítica e reflexiva, atribuindo nova responsabilidade à educação e às escolas de medicina, conforme assinala Ricardo Tapajós (2002, p. 30):

A educação médica passa, então a ter de se preocupar em formar médicos detentores não somente de técnica impecável, como também cuidadores humanizados, sensíveis, preparados para lidar consigo e com seus pacientes, tarefa que exige trabalhar com os mais diversos valores inseridos em complexos contextos históricos, culturais e sociais.

A formação do médico deve compreender alguns valores fundamentais em nome de uma prática profissional íntegra, visando ao bem-estar do paciente. A prática profissional encontra-se enredada em valores como competência, confiança, confidencialidade, relacionamento, qualidade de atendimento, responsabilidade social e ética. Os currículos devem enfatizar essa prática. A busca por formas de melhorar o relacionamento com o paciente é uma face dessa mudança e a comunicação pode oferecer amplas possibilidades eficiência, conforme afirma Isaac Epstein (2004, p. 1):

A boa comunicação pode aumentar a eficácia dos serviços de saúde. Ao nível da comunicação interpessoal isto começa a ser reconhecido oficialmente. Os problemas da adequação da comunicação médico-paciente que sempre existiram como questões periféricas começam a ser reconhecidos oficialmente inclusive como temas dos currículos de nossas escolas de medicina.

Fernando Albuquerque de Oliveira (2002, p. 64) assinala que uma das principais atribuições do médico é "traduzir o discurso, os sinais e os sintomas do paciente para chegar ao diagnóstico da doença”. Quando uma pessoa procura um serviço de saúde estabelece-se uma relação que "pressupõe uma comunicação com duas vias de fluxo, permitindo, no momento em que o indivíduo busca atendimento de saúde, o encontro de duas visões de mundo diferentes". Ainda segundo o mesmo autor, a pessoa "lança mão de uma série de mecanismos que orienta tal procura e que são acionados muito antes do encontro propriamente dito: quais os sintomas que a forçam ao encontro, qual o linguajar a ser utilizado" para descrevê-los, que roupa vestir etc.

Em última análise, como é que o indivíduo se prepara para esse momento, como se comporta nele e qual a 'bagagem' que carrega consigo? Portanto, quando mencionamos 'comunicação', também queremos dizer que há produção de significados de ambos os lados e que a cultura de cada grupo social estará igualmente presente (Oliveira, 2002, p. 65. Destaques do autor).

\footnotetext{
1 Destaque nosso.
} 
De acordo com Eduardo Ferreira, Maria Ribeiro e Sebastião Leal (2002, p. 77), a consulta é o momento mais importante para tomada de decisão, mas tem sido desvalorizado pela mercantilização do serviço: "fazer mais e mais em cada unidade de tempo". A desvalorização da consulta faz com que

a relação interpessoal seja insatisfatória, perdendo-se a oportunidade terapêutica que ela encerra. Aspectos vitais, como a confiança, a adesão ao tratamento, a formação de vínculo que possibilite a continuidade, a negociação e participação nas tomadas de decisão, são prejudicadas (Ferreira; Ribeiro; Leal, 2002, p. 74-75).

É preciso recuperar os princípios valorativos da consulta, preparando o médico para comunicar-se eficientemente com o paciente, para que consiga informações sobre o seu estado de saúde, estimulando sua autonomia e participação no tratamento. Isso implica romper com a forma usual de comunicação, na qual se evidencia o poder exercido pelo médico e a idealização social desse poder.

Originalmente, a palavra comunicação comporta dois sentidos: o de partilhar algo e o de dar conhecimento, informar. Como informação, a relação entre os sujeitos (emissor/receptor) é hierarquizada e menos sujeita a mudança (geralmente caracteriza sistemas autoritários). Como partiIhamento, trata-se de um processo horizontal, caracterizado pelo diálogo (um processo dinâmico de emissão/recepção e recepção/emissão), (re) construindo significados. É nesse sentido que entendemos a interação entre comunicação e saúde no âmbito do relacionamento médico-paciente, que tem se caracterizado pela verticalização (formas de interdição das falas, silêncios, passividade), impregnada do poder do médico (detentor do saber técnico), que inibe a manifestação do paciente. Tal verticalização pode explicar uma das reclamações mais comuns: a falta de atenção do médico. A esse respeito Graciela Natansohn (2004, p. 43) pondera que,

a partir dos [anos] 1970, uma concepção tecnocrática do saber médico, baseado num saber técnico superior e, portanto, autoritário em relação a quem não sabe; um enfoque cientificista, que nega outro saber que não seja o científico e se mostra como saber politicamente neutro, uma tendência medicalizante. Cada vez mais áreas da vida caem sob o controle da medicina, com a consequente reprodução ampliada das relações de poder que ela veicula. Além disso, consolida-se um enfoque mercantilista, pois a saúde passa a ser uma atividade lucrativa, uma mercadoria estabelecendo-se uma relação de mercado entre o médico e o doente.

Nesse contexto adquire força o movimento pela reaproximação da medicina de suas origens humanistas:

Mesmo sob o ponto de vista formal, a relação entre serviços de saúde e usuários envolve muitos outros aspectos além do encontro físico entre o médico e paciente num consultório, por exemplo. Há, entre outros fatores, as políticas de saúde em cada local e as concepções dos indivíduos sobre o que é estar doente. A doença é uma experiência que não se limita à alteração 
biológica pura, mas esta Ihe serve com substrato para uma construção cultural, num processo que Ihe é concomitante (Oliveira, 2002, p. 64).

A comunicação envolve todos os sentidos e ações das pessoas e determinado contexto. Pode atuar como facilitador ou como entrave à integração com o interlocutor. Há, contudo, uma forma de comunicação horizontal em que falar, intervir, participar são ações que se esperam do paciente. A mediação do relacionamento por essa forma pressupõe certas competências do médico. Mediação, porque a consulta é uma etapa do relacionamento, compreendida num contexto cultural, histórico e social que envolve os sujeitos (médico e paciente) e as instituições. Nesse momento crucial,

as qualidades pessoais do médico, sua cultura técnica e humanística e especialmente suas atitudes são fatores decisivos, destacando-se a capacidade de escuta e de comunicação. Atitudes positivas do médico, percebidas pelo paciente abrem caminho para que este se coloque mais à vontade, com informações mais completas, sinta-se seguro, confiante e disposto a aderir ao tratamento. Esta é a relação terapêutica (Ferreira; Ribeiro; Leal, 2002, p. 54-55).

Nesse mesmo sentido, Oliveira (2002, p. 67-68) pondera que,

em cada cultura, a doença, a resposta a ela, os indivíduos que a experienciam, os que se ocupam em tratá-la e as instituições envolvidas estão interconectados mediante esse sistema, que também contempla, entre outros elementos, as crenças sobre a origem das doenças, as formas de busca e avaliação do tratamento, os papéis desempenhados e as relações de poder entre todos os envolvidos. Os pacientes e os agentes de cura são componentes básicos do sistema, estando imersos num contexto de significados culturais e de relações, não podendo ser entendidos fora dele.

Desse modo, o ensino da relação entre médico e paciente se constitui em grande desafio para as escolas, para os currículos e também para as organizações em que esses profissionais trabaIham (ou trabalharão), precisando ser enfrentado de modo sistematizado, por meio da interface com a comunicação.

\section{CONSIDERAÇÕES FINAIS}

Nas palavras de Lampert (2002), a educação médica tem como um de seus principais desafios a superação da cisão entre formação e trabalho médico. Porém, a formação médica não está limitada ao âmbito da escola médica e aos seus projetos pedagógicos, mas diretamente ligada à complexidade dos processos sociais, aos processos de trabalho, às relações de produção, ao papel social das instituições, às condições do mercado de trabalho e às políticas públicas de saúde. Igualmente, a humanização das práticas médicas está diretamente ligada a esses mesmos processos. Envolve inescapevalmente sujeitos (médicos, pacientes e seus familiares). 
Sem perder de vista a complexidade da questão, neste artigo procuramos focalizar o papel das escolas médicas e a influência que exercem na organização dos serviços de saúde. As escolas médicas tem um compromisso social irrenunciável de formar profissionais técnica e socialmente competentes, por meio de currículos e metodologias inovadores. E nesse sentido é fundamental que considerem a contribuição das ciências sociais na formação integral do médico, superando a inutilidade dicotômica entre ciências naturais e ciências sociais denunciada por Santos (1995, p. 37-38). O autor afirma que a superação desta dicotomia tende a revigorar os estudos humanísticos, o que, segundo ele, não ocorrerá sem que as humanidades sejam, também, profundamente transformadas. Nessa perspectiva, a inserção de disciplina de comunicação no currículo de graduação pode contribuir para a prática eficiente e humanizada, preparando o profissional para escutar e se fazer ouvir. Ouvir e se fazer ouvir exige valoração da consulta, disponibilidade e técnicas. A comunicação como conhecimento organizado, sistematizado pode oferecer essa competência ao médico.

Por fim, cabe registrar que a perspectiva explorada neste artigo é uma entre tantas outras. Seja no âmbito da investigação científica ou da atuação profissional, a área da saúde ainda continua sendo um campo a ser explorado pela comunicação. Permanece a necessidade de avançar na análise das interfaces possíveis, já que os desafios são muitos e bastante complexos.

\section{REFERÊNCIAS}

ALMEIDA, Márcio José de. Ensino médico e o perfil do profissional de saúde para o século XXI. Interface - Comunicação, Saúde, Educação, v. 3, n. 4, fev. 1999. Disponível em: <www.interface.org.br/revista4/debates1.pdf>. Acesso em: 12 mar. 2004.

CARDOSO, Waldir. [01.12.2011]. Pesquisa CFM/Cremesp: número de médicos no Brasil cresce 21,3\% em uma década. Disponível em: <http://waldircardoso. wordpress.com/2011/12/01/pesquisa-cfmcremesp-numero-de-medicos-no-brasil-cresce-213-em-uma-decada/>. Acesso em: 12 mar. 2012.

BRASIL. Conselho Federal de Medicina / Conselho Regional de Medicina do Estado de São Paulo. Distribuição dos médicos nos setores público e privado da saúde. In: Demografia médica no Brasil: dados gerais e descrições de desigualdades. Vol. 1. São Paulo: CFM/Cremesp, 2011. Disponível em: <http://www.institutosalus.com/_arquivos/diversos/ demografia-medica-no-brasil.pdf>. Acesso em: 12 mar. 2012.

Ministério da Educação. Parecer CNE/CES 104/2002. Diretrizes Curriculares Nacionais do Curso de Graduação em Biomedicina. Disponível em: <http://portal.mec.gov.br/cne/arquivos/pdf/CES0104.pdf>. Acesso em: 12 mar. 2012.

Constituição de República Federativa do Brasil, de 05 de outubro de 1988. São Paulo: Atlas, 2003.

EPSTEIN, Isaac. Prefácio. Boletín Temático Comunicación y Salud, VI Conferência Brasileira de Comunicação e Saúde, São Paulo, Asociacion Latinoamericana de Investigadores de Comunicación - Alaic, 26/05/2004. Disponível em: <www.eca.usp.br/alaic/boletin16>. Acesso em: 12 mar. 2012.

FERREIRA, Eduardo Costa; RIBEIRO, Maria Mônica Freitas; LEAL, Sebastião Soares. Praticando a relação médico - paciente III: efeito terapêutico da consulta. Clínica Médica, v. 2, n. 1, Rio de Janeiro, Medsi - Editora Médica e Científica Ltda., 2002. 
FEUERWERKER Laura C. M.; SENA Roseni R. Construção de novos modelos acadêmicos de atenção à saúde e de participação social. In: ALMEIDA Márcio José de; FEUERWERKER, Laura C. M.; LLANOS, ManuelA. A educação dos profissionais de saúde na América Latina: teoria e prática de um movimento de mudança. São Paulo: Hucitec, 1999. p. 47-83.

GALIZZI FILHO, João. A relação médico-paciente e as instituições. Clínica Médica, Rio de Janeiro: Medsi - Editora Médica e Científica Ltda., v. 2, n. 1. 2002.

INSTITUTO SALUS. Número de cursos de medicina no Brasil cresce $82 \%$ em duas décadas. Disponível em: <http:// www.institutosalus.com/noticias/ medicina/numero-de-cursos-de-medicina-no-brasil-cresce-82-em-duas-decadas>. Acesso em: 12 mar. 2012.

LAMPERT, Jadete Barbosa. Tendências de mudanças na formação médica no Brasil: tipologia nas escolas. Tese (Doutorado em Saúde Pública) - Fundação Osvaldo Cruz, Escola Nacional de Saúde Pública, Rio de Janeiro, 2002.

NATANSOHN, Graciela. Comunicação \& saúde: interfaces e diálogos possíveis. Revista de Economia Política de Las Tecnologias de la Información y Comunicación, v. VI, n. 2, mayo-ago. 2004. Disponível em: <www.eptic.com.br>. Acesso em: 12 mar. 2012.

OLIVEIRA, Fernando Albuquerque de. Antropologia nos serviços de saúde: integralidade, cultura e comunicação. Interface - Comunicação, Saúde, Educação. Unesp, Botucatu, v. 6, n. 10 p. 63-74, 2002.

SANTOS, Boaventura de Sousa. Um discurso sobre as ciências. 7. ed. Porto, Portugal: Edições Afrontamento, 1995.

SCHEFFER, Mário. Introdução. In: SCHEFFER, Mário; BIANCARELLI, Aureliano; CASSENOTE, Alex (Coord.). Demografia médica no Brasil: dados gerais e descrições de desigualdades. São Paulo: Cresmep / CFM, 2011. Disponível em: <http://www.institutosalus.com/_arquivos/diversos/demografia-medica-no-brasil.pdf>. Acesso em: 12 mar. 2012.

SCHEFFER, Mário; BIANCARELLI, Aureliano; CASSENOTE, Alex (Coord.). Demografia médica no Brasil: dados gerais e descrições de desigualdades. São Paulo: Cresmep / CFM, 2011. Disponível em: <http://www.institutosalus. com/_arquivos/diversos/demografia-medica-no-brasil.pdf>. Acesso em: 12 mar. 2012.

TAPAJÓS, Ricardo. A introdução das artes nos currículos médicos. Interface - Comunicação, Saúde, Educação, Unesp, Botucatu, v. 6, n. 10, 2002.

Recebido em: 20.03.2012 / Aceito em: 31.05.2012 